\title{
NA ORIGEM ESTÁ O SIGNO
}

Lauro Frederico Barbosa da SILVEIRA*

RESUMO: A logica como semiótica implica, do ponto de vista de Peirce, uma estrutura triádica onde a bipolaridade constitulda pelo par sujeito-objeto é superada. Tanto o nominalismo quanto o individualismo são ultrapassados. O signo é mais amplo do que o símbolo e supõe a potencialidade e a atualidade. Duas classes de objetos e duas séries de interpretantes, cada uma destas últimas admitindo três espécies, dão lugar a uma lógica da conduta cientifica que faz apelo a uma comunidade futura cuja crença corresponde à Verdade, e a uma dimensão cosmológica do pensamento que fundamenta a derradeira objetividade do conhecimento e da volição.

UNITERMOS: Semiótica; objeto; interpretante; comunidade; pensamento.

\section{A SEMIÓTICA COMO CIÊNCIA NORMATIVA}

Após assumir a lógica dos relativos como fundamento as relações de pensamento, Peirce refaz pacientemente toda a organização do ediff́cio das ciências. Não pretende começar do nada, mas aperfeiçoar a tradição filosófica que o formou e com a qual criticamente conviveu. Hume e Kant estão presentes nesta tarefa e dela não se ausentam Francis Bacon, Berkeley, a Enciclopédia, Hegel e mais, recentemente, Augusto Comte.

Adotando as distinçōes entre as ciências das simples idéias e as ciências do fato de um lado, e entre as ciências gerais e as ciências especiais, de outro, estabelece a seguinte disposição sistemática:

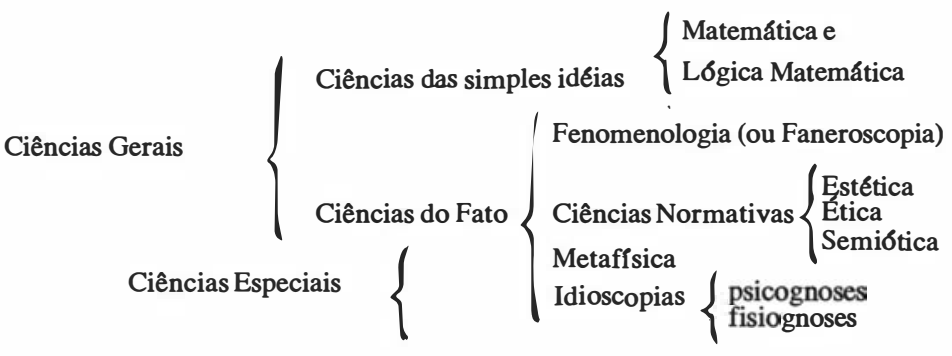

(Cf. 9. 1.176-202, 238-272,273-283)

\footnotetext{
* Departamento de Filosofia da Faculdade de Filosofia e Ciências - UNESP - 17500 - SP.
} 
Em primeiro lugar, diante deste quadro, cabe salientar que, apesar da separação humeana entre ciências das simples idéias e as ciências do fato, a matemática para Peirce não é analf́tica no sentido clássico do termo, mas construtiva; e que as ciências do fato não são originárias e redutivelmente indutivas. Como tambem, apesar da lógica ocupar um lugar na esfera das ciências das simples idéias e, junto com a matemática, emprestar o instrumental primeiro para a elaboração de qualquer outra ciência, ela compartilha do caráter construtivo da matemática, não lhe sendo atribufdo o estatuto meramente descritivo e analftico que Kant conferia à lógica geral.

Interessa-nos, no entanto, especialmente localizar a semiótica, com freqüência tomada por Peirce como sinônimo de lógica (Cf. 9. 2.227). Tudo poderia levar a crer que a semiótica seria equivalente à lógica transcendental kantiana e, certamente, há fundamento para tal aproximação: trata-se efetivamente da lógica referente ao universo da experiência e com esta comprometida. Acontece que as categorias para Peirce não correspondem às categorias kantianas e, como pretendemos ver adiante, não remetem a um "Eu penso" da apercepção transcendental; o próprio tempo não manifestará um eu fenomênico que polarize, a priori, a experiência na consciência individual.

Em Peirce, as categorias apresentam um caráter fenomenológico, procurando organizar indutivamente (e nisto, se assemelhando aos prinćpios humeanos) todo o campo do que nos aparece. São, entretanto, categorias verdadeiramente gerais, no sentido em que se aplicam a todo o campo da experiência, compondo-se entre si elementarmente (Cf. 9. 1.300-353, 417-480). Caso seja possfvel atribuir um lugar à transcendentalidade no interior do pensamento de Peirce, esta só poderá se encontrar - como propuseram Habermas e Apel, citando Peirce - assintoticamente no futuro, quando todas as hipóteses tiverem sido transformadas em hábitos e estes tiverem passado exaustivamente pelo crivo da experimentação (Cf. 1. 1. p. 394, 401-402; 1. 2. p. 28-30, 42-44, 51-53, 124, 159, 178-179, 182-183, 191-196, 200-201, 208-209, 242; 3. 1. p. 12, 55-56; 2. p. 155-158, 188, 196-208; 6. p. 95, $101,113-123,128-139$; 9. 1. 91, 612-613; 2. 299, 652-655, 5. 130-131, 198-200, 209-211, 315, 354-357, 365, 384 n1, 402, 406-408, 416-417, 421). Antes disto, todo conhecimento $\varepsilon$ falf́vel e não pode pretender alcançar a estrita universalidade e necessidade; não pode, por conseqüência, constituir, a priori, as condições objetivas da experiência.

A semiótica é uma ciência geral embora empírica que, sob forma prognóstica, procura estabelecer como devem ser os signos, ou como se constituirá o pensamento, para inteligência capaz de aprender com base na experiência (Cf. 9. 1.281; 2.227).

Tratando-se de uma lógica da conduta, cabe à semiótica representar o objeto como objeto de volição e o meio pelo qual racionalmente alcançá-lo. Deste modo, é precedida não só pela representação categorial da experiência, como pela representação da admirabilidade com que se apresentam os fenômenos e pela volição do fenômeno como objeto da conduta. Restringe-se, no entanto, somente ao objeto enquanto representado para a conduta e não se pronuncia quanto à realidade do mesmo ou quanto 
aos seus modos especiais de ser. Tais tarefas, como para Kant, cabem, respectivamente, à metafísica e às ciências especiais (Cf. 9. 1.190-202, 484-514, 530-544, 120-150).

A proposta peirceana, freqüentemente autodenominada realista escolástica, idealista objetiva ou do senso comum crftico, opõe-se antes de tudo ao nominalismo. No vocabulário de Peirce, esse termo designa mais do que uma escola particular, uma tendência que pervade toda a formação filosófica ocidental. É nominalista a concepção de conhecimento que polariza a representação, separando o discurso do existente. Se nem todo filósofo foi integralmente nominalista, quase todos - inclusive o próprio autor - cederam a tais pressupostos na constituição de suas doutrinas. Bipolar, tal tendência acaba postulando um incognoscivel aquém ou além do domínio da ciência (Cf. 9. 1. 16-18, 170, 422; 2.166-168; 3.460; 4. 1. 33-37, 68, 611; 5. 48, 59-63, 121; $6.270,492-493,505-506 ; 8.17-38,208 ; 10.4$. p. 295). O objeto, do ponto de vista da semiótica, contudo, precede à representação e dela não se aliena. A representação é o programa da conduta futura para ótima, mas falivelmente alcançar o objeto que a motiva, atraindo-a. Tal objeto, tanto quanto a representação, pertencem ao universo da experiência, não cabendo estabelecer qualquer antagonismo originário entre ambos.

Rompido o impasse nominalista, o que nem a Crltica tinha conseguido plenamente, cabe verificar qual a melhor representação que pode ser feita das relações cognitivas.

\section{A ESTRUTURA TRIÁDICA E DIALÓGICA DO SIGNO-PENSAMENTO}

A bem da verdade, a identificação do pensamento com o signo e a estrutura triádica deste último precedem à reformulação das categorias e à sistematização das ciências, acima apresentada.

Parece-nos, contudo, que realizadas algumas modificações nas atribuições dos correlatos do signo, este encontra sua plena oportunidade de explicitação ao ser estruturado segundo as três categorias fenomenológicas (Cf. 13. p. 179, 189-194).

Sem pretender alongarmo-nos discutindo diversas formulações fornecidas por Peirce, podemos dizer que o signo (ou representamen) $\varepsilon$ algo que sob algum aspecto ou qualidade (seu fundamento), fica no lugar de um outro (seu objeto), determinando na mente um outro signo (seu interpretante). Este último signo interpreta as relações constitutivas do próprio signo; relacionar-se-á com o objeto segundo um fundamento no máximo tão forte quanto o do representamen que o determina, e dará origem a uma série de si infinita de outros interpretantes. Esta série constituirá tendencialmente o significado do signo e, finalmente, assumirá o caráter de lei ou hábito de conduta face ao objeto (Cf. 9. 2. 233-264, 274-308).

Embora tenha havido quem, como Douglas Greenlee (Cf. 5. p. 59-69, 86-93, 106-111), tentasse suprimir, como superflua, a relação de objeto e reduzi-la à relação de interpretante, adotando para o signo um estatuto eminentemente convencional e formal que o confundia pura e simplesmente com o símbolo, não resta dúvida que Peirce insiste na especificidade e na mútua irredutibilidade dos três correlatos 
(Cf. 9. 4. 539, 5. 474). Com efeito, a cada um deles são atribufdas funções distintas e complementares: poder representar, $\in$ a caracteristica do representamen; atuar e resistir, caracterizam o objeto e mediatizar, caracteriza o interpretante. Deve-se, todavia, relembrar que tais funções são elementares e que, embora identifiquem-se com cada um dos correlatos, não são incompatf́veis ao serem atribứdas a um meio sujeito. Certamente o que, como representamen, se coloca presentemente no lugar do objeto, exerce também a função de interpretante da relação de um representamen anterior para com o objeto e compartilha, deste modo, do significado do signo. $\mathrm{O}$ mesmo pode-se dizer das funções que, no futuro, serão exercidas pelo interpretante. Mesmo o objeto de um signo que permanece o mesmo numa série interpretativa, pois é dele o significado que está sendo instaurado, pode exercer as funções de representamen ou de interpretante em outras instâncias da semiose, sob a forma de nfveis subordinados de significação (Cf. 4. p. 54-55; 9. 6. 490; 221.222).

Do caráter elementar das funções do signo e das categorias que as presidem, decorre também a reprodução em infinitos niveis, da tríade que elas constituem (Cf. 5. p. 33-42). Permite-se, então, o desdobramento indefinido de cada função, tornando-se, sobremodo, minuciosa a análise semiótica do pensamento (Cf. 14. p. 126-135). Impede-se, igualmente, qualquer tentativa de reificação das classificações delas deduzidas. Como exemplo desta aplicação infinita da mesma tríade, tem-se a divisão dos argumentos, de si mesmos uma das classes de interpretantes lógicos. Os argumentos seriam de três tipos: a abdução ou retrodução, a indução e a dedução. A indução, por sua vez, desdobrar-se-ia em indução ordinária, indução qualitativa e indução quantitativa. A primeira caracteriza-se por um fundamento meramente potencial, já que infere a confiabilidade de uma hipótese implicitamente formulada pela mera ausência de indices de uma realıdade contrária; a segunda, pela diferença não denumerável da efetivação de qualidades em situações de fato, não permitindo conclusões extensionalmente ampliativas; a terceira, ao permitir um tratamento estatístico dos dados obtidos e a generalização de uma razão de freqüência sob a forma de uma lei sui generis (Cf. 9. 2. 269, 755, 775-783; 8. 227-229; 11. p. 22-23, 160-166).

Como lógica da conduta cientiffica no universo da experiência e determinante de relações genuinamente gerais, a semiótica necessita levar em consideração o quadro geral das relações que o signo-pensamento estabelece consigo mesmo, com os objetos componentes do universo da experiência e com a dimensão temporal infinita, na qual a conduta racional se estabelece e se desenvolve.

Se bem, pois, que a triade de correlatos constitutivos do signo-pensamento seja matricialmente formada pelo representamen, o objeto e o interpretante, já que o fundamento não parece propriamente se distinguir do representamen, somente a relação de representamen, como mera potencialidade, é indecomponfvel e não necessita sof rer desdobramentos (Cf. 8. p. 305, 316-321; 14. 135-138). O objeto, na alteridade que lhe e própria, desdobra-se em objeto imediato e objeto dinâmico do signo. $O$ primeiro guarda da alteridade, o que o próprio signo representa, enquanto o segundo é exterior ao signo, mas não a toda semiose, e verifica em última instância a verdade do signo (Cf. 9. 4. 536-540; 5. 473; 6. 339; 8. 183, 343). Charles Morris denominou-os, 
respectivamente, significatum e denotatum. O conjunto constiturdo, no texto peirceano, pela conotação, a denotação e a informação poderia também designá-los, já que por sua conjunção o objeto é representado em suas características gerais, é indicado e sobre ele é determinado um jứzo de existência (Cf. 7. p. 93-96; 9. 1. 559; 2. 293, 473 ; 3. 608; 5. 474; 7. 221-222).

$\mathrm{O}$ interpretante complexifica-se muito mais, desdobrando-se em duas séries, sobre cujas relações recíprocas não há, entre os estudiosos, unanimidade de opinião.

Parece-nos que a posição adotada por T. A. Short, desde 1981, é a que melhor dá conta dessas relações e tem contado recentemente com a aceitação de outros competentes estudiosos do pensamento peirceano (Cf. 15; 16; 17; 18; 19). Defende a especificidade e independência recíproca de ambas as séries, parecendo-nos possível construir com elas, um quadro de dupla entrada, possibilitando classificá-las.

Intersecção das séries de interpretantes

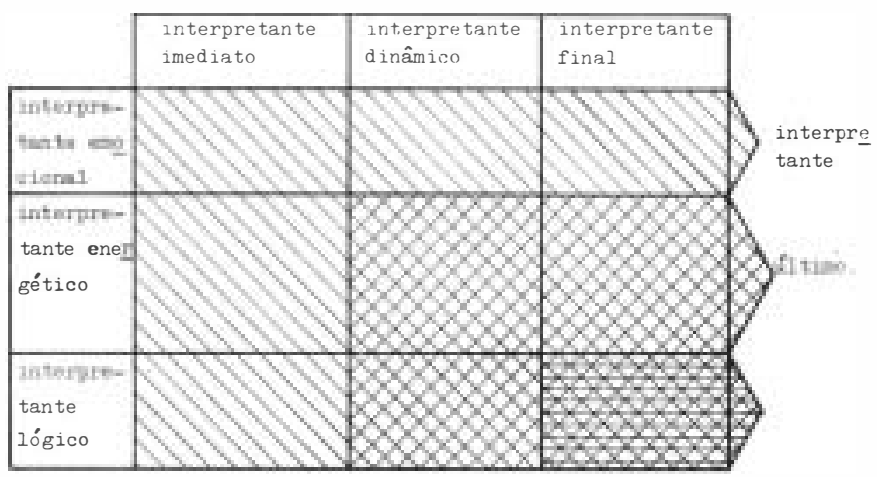

Uma das séries seria constiturda pelos interpretantes imediatos, dinâmico e final do signo, análogos aos que foram propostos para a relação de objeto. O interpretante imediato estaria representado na potência do signo, como a espécie de interpretação facultada pelo signo das relações do representamen e do objeto; o interpretante dinâmico seria a efetiva interpretação e o interpretante final, aquele ao qual tende a série futura das interpretações (Cf. 9. 4. 536-540; 5. 470-494).

A outra, seria formada pelos interpretantes emocional, energético e lógico. O primeiro $\mathfrak{e}$ uma mera disponibilidade, sentimento ou afeição que, rompendo um estado de indiferença, simplesmente predispõe a conduta diante do signo para encaminhar-se em busca do objeto. Desfeitas as repercussões psicologicas da exposição, trata-se de um interpretante de mera possibilidade. $O$ segundo, e uma ação que interpreta a relação do signo para com o objeto: a resposta a um comando e toda reação, são exemplos característicos e formas aproximadamente genuinas de interpretantes energéticos. Finalmente, o terceiro é uma representação que interpreta a relação do representamen e o objeto. A conhecida divisão da relação do interpretante em Rema, Dicente e Argumento e, no interior deste último, em abdução, indução e dedução, 
são realizações tŕpicas do interpretante lógico (Cf. 9. 2. 263, 266-270; 5. 470-486; 11. p. 22-23; 160-166).

Como nem todo representamen e nem todo objeto determinam do mesmo modo e com o mesmo grau de generalidade a conduta, e como esta última, na medida em que É representada pelo interpretante, não é sempre idêntica relativamente à relação do representamen e do objeto, mas pode responder com determinação variável a tal relação, nem sempre a cadeia de interpretantes se desenvolve indefinidamente. $O$ termino da cadeia pode ser um interpretante emocional, um energético ou um lógico (Cf. 9. 5. 474). Somente neste último caso, como pode ser visto no quadro (página anterior), distingue-se totalmente o interpretante final do interpretante dinâmico e, $a$ fortiori, do interpretante imediato. O interpretante intencionado, ou significado, corresponderia a esta última intersecção (Cf. 9. 5. 175-179; 475-476). Quando um ato faz cessar a cadeia interpretante, levando-a a termo, o interpretante dinâmico ocupa também a função do interpretante final; quando a interpretação permanece meramente potencial, não há por onde distinguir-se o interpretante final do interpretante imediato do signo (Cf. 9. 5. 475-476; 489-491).

Embora os textos não sejam suficientemente claros, pode-se aventar a hipótese de que, diante das possibilidades graduais de realização das séries interpretantes, Peirce tenha introduzido a denominação interpretante último para designar aquele com o qual cessa uma série interpretativa. A tal interpretante não se seguiriam outros, mas ele assumiria o caráter de um hábito de relacionar-se ao objeto (Cf. 9. 5. 476-483; 487). Estaria assim exclứda a progressão infinita da série interpretativa e manifestada a inserção estrutural da semiose na realização plena do ato volitivo inicial. $\mathrm{O}$ objeto extremo seria o próprio objeto dinâmico, finalmente acessível. Esta $E$ a interpretação conferida recentemente à relação entre interpretante último e objeto dinâmico por Sandra Rosenthal (Cf. 12), interpretação que encontra antecedentes em textos do próprio Peirce (Cf. 9. 8. 183). David Savan, já em 1977 (Cf. 13. p. 191-194), identificava o objeto dinâmico com o mundo parcial ou totalmente representado. Apel e Habermas, como já foi mencionado, ao lerem Peirce, atribuem à comunidade futura de interpretação o papel transformador da representação em hábito. Peirce antecipava este longo esforço de intelecção, ao identificar o interpretante final de todos os universos de percepção e, conseqüentemente, do objeto em sua totalidade com a própria Verdade (Cf. 9. 4. 539).

Supondo-se ser esta a estrutura do signo-pensamento para Peirce em seus escritos da maturidade, cabe novamente notar que nada que se refira à experiência à semiose. O proprio objeto, embora determinante do processo cognitivo, completa-o em seu final mas a ele não se furta, pois incorpora-se ao hábito, interpretante último do signo. O sujeito, por sua vez, constitui-se e desenvolve-se somente no interior do signo. Como consciência de si, atualiza-se como reagente na interpretação energética do objeto que se opõe à espontaneidade que o constitufa e da qual não tinha experiência. Como representação no futuro, projeta-se, explicitamente ou não, como comunidade de interpretação portadora de dimensões cósmicas e cuja crença constitui tendencialmente a verdade (Cf. 9. 5. 421). No presente, o sujeito apresenta-se como possibilidade de produzir representamina capazes de romper os limites do fato passado e de determinar, sob a forma interpretante, a conduta futura. 
A natureza do objeto e do sujeito é tal que faz com que a semiótica assuma, em sua estrutura, as funções de representamen, de objeto e de interpretante, e não a de intérprete. Este, no texto peirceano, só aparece de modo acidental, para satisfazer os preconceitos dos interlocutores (Cf. 11. p. 80-81).

Não é igualmente gratuita a afirmação ao longo da obra peirceana, de que é a comunidade, e não o indivíduo, que exerce plenamente o pensamento. Em relação ao interpretante último, ela assume uma dimensão cósmica ao unir-se ao próprio objeto em sua plena realidade (Cf. 14. p. 139-142).

O signo, por definição, é um mediador; não se reduz, contudo, a um meio ou instrumento que tentasse transpor a barreira que separaria dois pólos antagônicos em constante disputa por hegemonia. Se tal conclusão relembra Hegel na introdução à Fenomenologia do Esplrito, os correlatos do signo, porém, não se negam nem se suprimem: a potência do presente e do representamen é espontaneidade, mas não indeterminação e o interpretante não ocupa o lugar do absoluto, mesmo que provisória ou ilusoriamente. O signo-pensamento $\hat{e}$, antes de mais nada, constante e evolutivo remetimento, num tempo cósmico e objetivo, dos seus correlatos, em todos os níveis de sua realização.

Apesar da aparência que tem sustentado diversas doutrinas filosóficas, se for tomado o ponto de vista de Peirce, quer na origem, quer no telos, tudo é signo e nada é fixo.

SILVEIRA, L. F. B. da. In the origin is the sign. Trans/Form/Ação, São Paulo, v. 14, p. 45-52, 1991.

ABSTRACT: Logic as semiotics implies, in the Peirce's point of view, a triadic structure of thought and sign, where the bipolarity constituted by the pair subject - object is overcome. Nominalism is surpassed and individualism too. Sign is broader than symbol and supposes potentiality and actuallity. Two classes of objects and two series of interpretants, each one of the least by its turn admitting a triple subdivision, give place to a logic of scientific conduct. This makes appeal to a future community whose belief corresponds to the Truth, and to a cosmologic dimension of thought that supplies with a ground to the last objectivity of knowledge and volition.

KEYWORDS: Semiotics; object; interpretant; community; thought.

\section{REFERÊNCIAS BIBLIOGRÁFICAS}

1. APEL, K. O. Charles Sanders Peirce and the post-tarskian problem of an adequate explication of the meaning of truth: towards a transcendental theory. Part I. The Monist, La Salle, v. 63, p. 386-407, 1980. Part II. Transactions of the Charles S. Peirce Society. Buffalo, v. 18, n. 1, p. 3-17, 1982.

2. APEL, K. O. Charles S. Peirce: from pragmatism to pragmaticism. Amherst: University of Massachusetts Press, 1981.

3. APEL, K. O. La transformación de la filosofia. Madrid: Taurus, 1985, v. 1 e 2. 
4. BENSE, M. Pequena estética. São Paulo: Perspectiva, 1971.

5. GREENLEE, D. Peirce's concept of sign. The Hague: Mouton, 1973.

6. HABERMAS, J. Knowledge and human interests. London: Heinemann, 1972.

7. MORRIS, C. Writings on the general theory of signs. The Hague: Mouton, 1971.

8. NESHER, D. Are there grounds for identifying "Ground" with "Interpretant" in Peirce's pragmatic theory of meaning? Transactions of the Charles S. Peirce Society, Buffalo, v. 20, n. 3, p. 303-324, 1984.

9. PEIRCE, C. S. Collected papers of Charles S. Peirce. Edited by Hartshorne, Weiss and Burks. Cambridge, MA: Harvard University Press, 1958, 1974. v. 1-8.

10. PEIRCE, C. S. The new elements of mathematics. Edited by Carolyn Eisele. The Hague: Mouton, 1976. v. 1-4.

11. PEIRCE, C. S., WELBY, V. L. Semiotics and significs: the correspondence between Charles S. Peirce and Victoria Lady Weeby. Edited by Charles S. Hardwick. Bloomington: Indiana University Press, 1977.

12. ROSENTHAL, S. B. Peirce Peircés ultimate logical interpretant and dynamical object: a pragmatic perspective. Transactions of the Charles S. Peirce Society, Buffalo, v. 26, n.2, p. 195-210, 1990.

13. SA VAN, D. Questions concerning certain classifications claimed for signs. Semiotica, The Hague, v. 19, n. 3/4, p. 179-196, 1977.

14. SAVAN, D. Response to T. A. Short. Transactions ot the Charles S. Peirce Society, Buffalo, v. 22, n. 2, p. 125-144, 1986.

15. SHORT, T. A. David Savan's Peirce studies. Transactions of the Charles S. Peirce Society, Buffalo, v. 22, n. 2, p. 89-124, 1986.

16. SHORT, T. A. Life among legisigns. Transactions of the Charles S. Peirce Society, Buffalo, v. 18, n. 4, p. 285-310, 1982.

17. SHORT, T. A. Peirce's conception of final causation. Transactions of the Charles S. Peirces Society, Buffalo, v. 17, n. 4, p. 369-382, 1981.

18. SHORT, T. A. Semeiosis and intentionality. Transactions of the Charles S. Peirce Society, Buffalo, v. 17, n. 3, p. 197-223, 1981.

19. SHORT, T. A. Some problems concerning Peirce's conceptions of concepts and propositions. Transactions of the Charles S. Peirce Society, Buffalo, v. 20, n. 1, p. 20-37, 1984. 984. 